\title{
Clinical Scenario of the Metabolic Syndrome
}

\author{
Swantje Brede Georg Serfling Johanna Klement Sebastian M. Schmid Hendrik Lehnert
}

Department of Medicine I, University of Lübeck, Lübeck, Germany

\section{Keywords}

Metabolic syndrome - Cardiovascular disease . Insulin resistance $\cdot$ Abdominal obesity $\cdot$ Hyperlipidemia

\section{Summary}

The term metabolic syndrome (MeS) refers to a cluster of associated symptoms composed of impaired fasting glucose, abdominal obesity, hypertension, and dyslipidemia. MeS is associated with an increased risk of cardiovascular and diabetes-associated morbidity and mortality. The increased amount of visceral fat together with a chronic inflammatory state predisposes to the development of arteriosclerosis. Furthermore, insulin resistance (IR) and dyslipidemia are associated with fatty liver disease. In addition, MeS is linked to non-cardiovascular diseases such as cancer as well as psychiatric or endocrine disorders. Here, we discuss the clinical impact of $\mathrm{MeS}$ in cardiovascular and non-cardiovascular diseases to highlight the importance of prevention, early diagnosis, and multifactorial treatment of high-risk individuals.

(C) 2016 S. Karger GmbH, Freiburg

\section{Cardiovascular System}

\section{Fat Distribution}

The metabolic syndrome $(\mathrm{MeS})$ increases overall cardiovascular mortality by a factor of 1.5-2.5 [1]. Over the last decades, the relevance of fat distribution for the development of cardiovascular disease (CVD) and metabolic disorders was recognized despite the finding of so-called metabolically healthy obese people, a phenomenon first described by Sims about 15 years ago [2]. Localization of the excess amount of adipose tissue appears to be a key for developing cardiovascular and metabolic diseases. Furthermore, in contrast to subcutaneous fat, excess visceral fat increases the risk for developing insulin resistance (IR) and other features of MeS [3].
The waist-to-hip ratio appears to be superior to the body mass index (BMI) when assessing the individual disease risk since it identifies people with a relatively low BMI but increased intra-abdominal fat accumulation [4]. In line with these findings, it has been shown that the waist-to-hip ratio and waist and hip circumferences are superior to BMI in predicting the risk of myocardial infarction [5]. An even better diagnostic parameter of visceral fat than waist circumference alone appears to be the combination of an increased waist circumference and elevated fasting triglyceride concentrations [6]. It has been shown that high triglycerides together with elevated waist circumference are associated with a higher cardiometabolic risk profile, as displayed by a hazard ratio for future coronary artery disease of 2.40 in men and of 3.84 in women [7]. Beyond the risk for coronary heart disease, excess visceral fat has been found to be associated with hypertension [8]. In comparison to other influencing factors, the waist circumference in men and women showed the strongest association to systolic and diastolic blood pressure [9].

The pathophysiological link between visceral fat and cardiovascular disease is certainly multifactorial. One mechanism might be the association of visceral and ectopic fat accumulation, e.g. fatty degeneration of cardiac cells. It has been shown that visceral obesity is the best predictor for epicardial and pericardial fat [10]. Moreover, weight loss associated with a decrease of visceral fat in severely obese subjects significantly reduces epicardial fat thickness [11]. Pericardial fat correlates with adiposity, vascular calcification, and further cardiovascular risk factors [12]. In particular, epicardial fat appears to be related to the presence, severity, and recurrence of atrial fibrillation as a most critical factor for stroke [13]. Visceral adiposity in contrast to subcutaneous fat facilitates arteriosclerosis, hypertension, and fat accumulation of the heart, thereby heralding an increased risk of CVD (fig. 1).

\section{Chronic Inflammation in Adipose Tissue}

Chronic low-grade inflammation caused by activated macrophages in visceral adipose tissue may also contribute to cardiovascular risk in patients with MeS [14]. It has been shown that low C-reactive protein (CRP) levels in metabolically healthy obese pa-

\section{KARGER}

() 2016 S. Karger GmbH, Freiburg

Fax +497614520714 


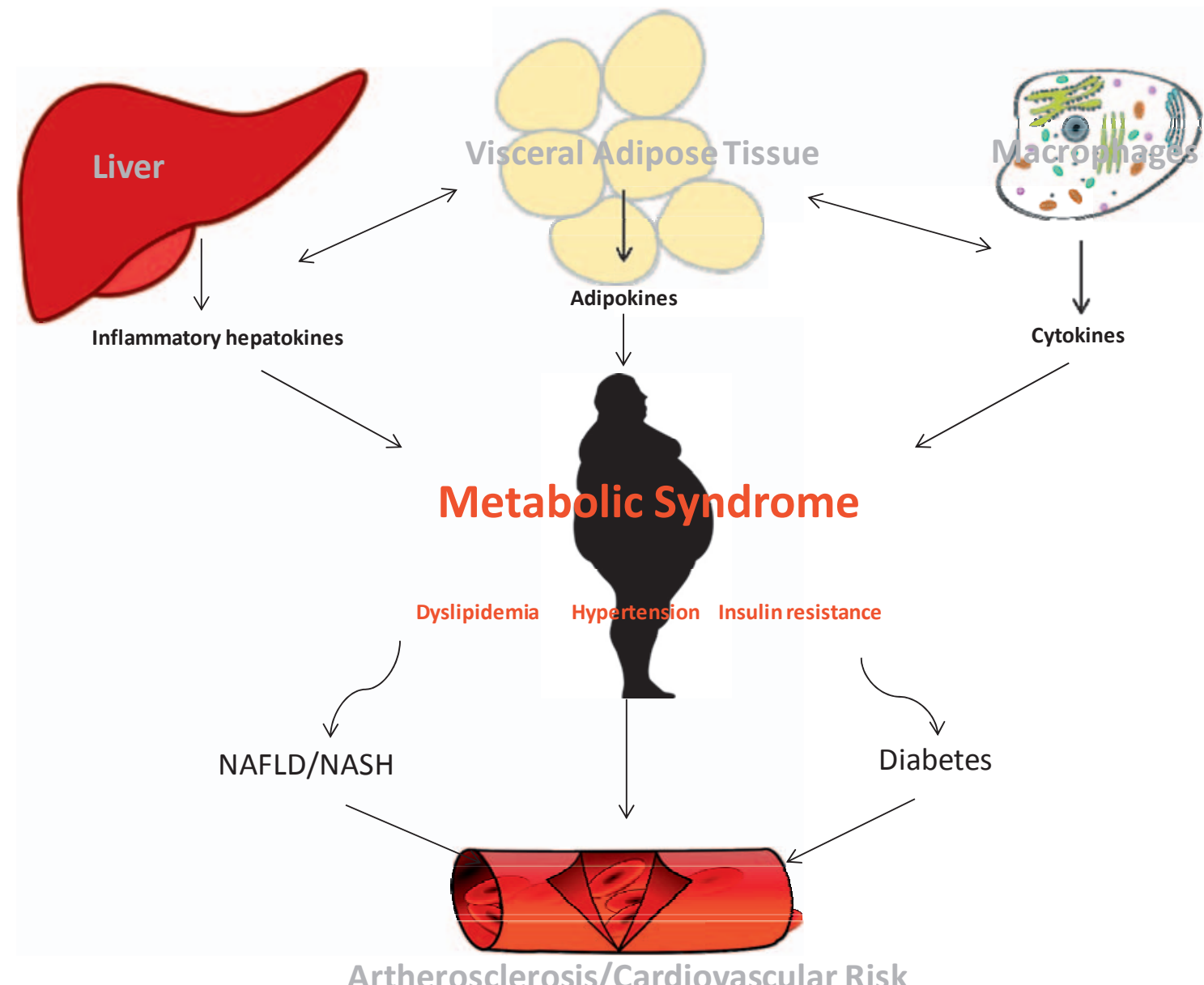

Pathogenesis of elevated cardiovascular risk in the MeS.

tients were associated with a similar risk for CVD as compared to metabolically healthy normal-weight persons [15]. The mechanism of obesity-related inflammation is not fully understood yet. One possible explanation is obesity-induced systemic oxidative stress, which leads to a stimulation of NADPH oxidase activation, thereby disrupting normal adipocytokine profiles [16]. Adipose tissue of obese patients expresses large amounts of proinflammatory cytokines such as tumor necrosis factor (TNF)-alpha or interleukin (IL)-6. Furthermore, adipose tissue macrophages are elevated in obesity and perpetuate inflammatory pathways, e.g. by being responsible for almost all adipose tissue TNF-alpha expression [17].

\section{Leptin and Other Adipokines}

The probably most relevant adipokine is leptin, whose main role resides in signaling peripheral energy status to the brain. Its key physiological functions are to reduce appetite, increase energy expenditure, and improve insulin sensitivity [18]. Leptin is mostly synthetized and secreted by white adipocytes [19]. It has been shown that hyperleptinemia is associated with CVD such as atherosclerosis [20]. The development of leptin resistance, in analogy to IR, appears to be of major relevance for the genesis and maintenance of obesity. This resistance may occur at several sites, namely at the blood-brain barrier and at specific hypothalamic nuclei such as the arcuate nucleus and other nuclei associated with reward-re- lated eating behavior [21]. Bypassing the blood-brain barrier may represent a means to overcome at least one site of this resistance [22]. In conclusion, elevated leptin levels and leptin resistance are associated with obesity, IR, myocardial infarction, and congestive heart failure [23].

Adiponectin, an adipocyte-derived protein, is an important adipokine protective for the development of MeS and capable of increasing insulin sensitivity [24]. Adiponectin suppresses glucose production in the liver and enhances fatty acid oxidation in skeletal muscle, resulting in beneficial metabolic sequelae [25]. Adiponectin levels have been shown to be significantly reduced in obesity [26]. With regards to chronic inflammation processes, this peptide is inversely associated with CRP levels independently of all other MeS factors [27]. Moreover, adiponectin appears to play a major role in the central regulation of energy metabolism. As such, adiponectin complexes have been shown in human cerebrospinal fluid [28]. In animal models, intracerebroventricular injection of adiponectin led to a decrease in body weight and an increase in energy expenditure [29].

Effects for the development of CVD also exist for homocysteine, a product of demethylation of methionine. This amino acid appears to be relevant in the pathogenesis of atherogenesis by inducing prothrombotic and proinflammatory effects, increased oxidative stress, endothelial dysfunction, and smooth muscle cell prolif- 
eration [30]. Elevated plasma homocystein levels are associated with increased cerebro-cardiovascular events in MeS [31]. In obese patients, homocysteine concentrations are elevated and correlate well with serum levels of leptin [32].

\section{Insulin Action}

Impairment of insulin action is one key feature of MeS. Conceptually, both IR and impaired pancreatic insulin secretion lead to a decrease of insulin action. It has been shown that IR contributes to the development of arteriosclerosis [33], thereby increasing cardiovascular risk. Furthermore, IR may contribute to other cardiovascular risk factors such as increased blood pressure, dyslipidemia, and diastolic dysfunction [34]. A major risk factor for the development of IR is visceral obesity [35]. Increased waist circumference, skin alterations like pseudoacanthosis nigricans, and fatty liver disease might serve as clinical indicators for IR.

IR may occur in several tissues, e.g. also in the brain as a socalled 'central insulin resistance' among other factors induced by excessive intake of calories and saturated fatty acids [36]. As a consequence, this may lead to attenuated satiety signals and increased hunger. IR in the liver is followed by increased glucose production due to insufficient suppression of gluconeogenesis. Moreover, excessive delivery of free fatty acids from adipose tissue further perpetuates hepatic IR and promotes non-alcoholic fatty liver disease (NAFLD) [37]. NAFLD, being tightly correlated with hepatic IR [38], is a strong predictor for the development of diabetes mellitus type 2 [39]. Further progression of NAFLD triggers hepatic inflammation, i.e. steatohepatitis leading to fibrosis and even cirrhosis [40]. Moreover, IR of adipose tissue leads to elevated levels of triglycerides and free fatty acids as a consequence of increased lipolysis [41]. Accumulation of fatty acids in the pancreas might further result in diminished insulin secretion from pancreatic $\beta$-cells [42, 43]. Impaired insulin secretion in combination with IR further worsens the metabolic consequences of MeS.

\section{Lipid Metabolism}

Another key feature of MeS is dyslipidemia as characterized by elevated levels of triglycerides and free fatty acids as well as decreased levels of high-density lipoproteins (HDL) [44]. Low-density lipoproteins (LDL) and total cholesterol levels are mostly within the normal range, while HDL and LDL particles are smaller in visceral obesity and MeS [45]. This is driven by an exchange of cholesterol ester molecules against triglyceride molecules in the core of the lipoproteins. Subsequently, HDL and LDL particles are more likely to deliver their lipid content to the liver, thereby forming small dense particles [46]. This dyslipidemic state is one of the main risk factors for developing arteriosclerosis [47]. Whether hypertriglyceridemia represents an independent risk factor is not yet verified in humans [48], but remnants of triglyceride-rich lipoproteins are highly atherogenic [49]. The low density and altered
Table 1. Association between obesity and relative risk of cancer: meta-analysis of studies from 1985-2011 (modified according to [80])

\begin{tabular}{lll}
\hline \multirow{2}{*}{ Cancer } & \multicolumn{2}{l}{ Relative risk (95\% confidence interval) } \\
\cline { 2 - 3 } & women & men \\
\hline Esophagus & $2.04(1.18-3.55)^{\mathrm{a}}$ & $1.23(0.58-2.60)$ \\
Colon & $1.19(1.04-1.36)^{\mathrm{a}}$ & $1.57(1.48-1.65)^{\mathrm{a}}$ \\
Rectum & $1.03(0.74-1.44)$ & $1.22(0.91-1.64)$ \\
Pancreas & $1.34(1.22-1.46)^{\mathrm{a}}$ & $1.36(1.07-1.73)^{\mathrm{a}}$ \\
Gallbladder & $1.82(1.32-2.50)^{\mathrm{a}}$ & $1.47(1.17-1.85)^{\mathrm{a}}$ \\
Thyroid gland & $1.03(0.87-1.23)$ & $1.12(0.72-1.72)$ \\
Non-Hodgkin lymphoma & $0.91(0.86-0.97)^{\mathrm{a}}$ & $1.09(0.98-1.21)$ \\
Breast, postmenopausal & $1.25(1.07-1.46)^{\mathrm{a}}$ & - \\
Kidney & $1.72(1.58-1.88)^{\mathrm{a}}$ & $1.57(1.38-1.77)^{\mathrm{a}}$ \\
\hline
\end{tabular}

aStatistically significant $\mathrm{p}<0.05$.

structure of LDL cholesterol in MeS particularly promotes the development of arteriosclerosis by stimulating resident macrophages and triggering inflammation within the vascular wall [50]. Less effective binding to the LDL receptor also attenuates the clearance of small LDL particles. Furthermore, expression of the LDL receptor is reduced in the presence of IR. Antiatherogenic features of HDL are based on an increased cholesterol efflux from the vascular wall and inhibition of the uptake of LDL into macrophages [51].

\section{Other Obesity-Associated Diseases}

\section{Cancer}

In $\mathrm{MeS}$, there is an increased risk for developing cancer with sex-specific differences (table 1). However, there is still a debate on the underlying mechanisms. Again, IR, hyperinsulinemia, and chronic subclinical inflammation might directly and indirectly promote cellular dedifferentiation and thus tumorigenesis. Due to stimulation of cell survival, cell proliferation, and angiogenesis, cancer progression is facilitated [52]. Insulin acts as a growth factor, and hyperinsulinemia, as often prevalent in MeS, may cause a more rapid and aggressive growth of cancers such as colorectal carcinoma, pancreatic carcinoma, liver cancer, and others [53]. Adipocytes represent a central mediator of the inflammatory response in obese patients. They are secreting not only proinflammatory cytokines or adipokines but also growth factors such as insulin-like growth factor 1 or vascular endothelial growth factor. Through these growth factors, PI3K/Akt signaling is stimulated, which is involved in the regulation of cell survival, cell proliferation, and cell migration. Thus, chronic inflammation in adipose tissue promotes hyperplasia, tumor growth, and metastasis formation [52]. Moreover, abdominal obesity induces significant changes in adipose stem cells, which may initiate breast cancer formation through estrogendependent pathways (table 1) [54].

\section{Hyperuricemia}

In recent years, hyperuricemia has been recognized as a part of $\mathrm{MeS}$, since high serum uric acid is clearly correlated with the prev- 
alence of MeS [55]. Furthermore, higher levels of serum uric acid increase the risk of developing type 2 diabetes [56] and are associated with several components of MeS such as IR [57], hypertension [58], and arteriosclerosis [59]. Atherogenic effects are probably mediated by higher activity of pro-oxidant in comparison to antioxidant forms of xanthine oxidoreductase. Increased vascular inflammation may result from this alteration $[60,61]$.

\section{Blood Clotting}

Impaired blood clotting has been observed in MeS, which increases the risk for cardiovascular events [62]. Beside atherothrombotic cardiovascular events, there is also a higher rate of thromboembolism. Both are provoked by reduced activity of vasodilators and an increased expression of vasoconstrictors as a consequence of endothelial dysfunction. This dysfunction appears to result from chronic inflammation, dyslipidemia, and hypertension. Furthermore, a higher platelet activity and enhanced coagulation, displayed by higher fibrinogen and plasminogen activator inhibitor levels, are observed [63]. Enhanced coagulation could be caused by altered hepatic production of coagulation factors and proinflammatory cytokines because of hepatic IR [64]. In addition, there is evidence for an influence of several adipokines, such as leptin and adiponectin, on platelet function [65].

\section{Psychiatric Disorders}

Depressive disorders are often associated with metabolic disturbances like hypertension, increased cardiovascular risk, chronic inflammation, and altered insulin signaling [66]. The prevalence of $\mathrm{MeS}$ is threefold higher in patients with psychiatric disorders compared to the general population. This includes depression, bipolar disorders, and schizophrenia [67]. Numerous mechanisms behind these findings are being discussed, encompassing vascular changes, subclinical hypercortisolism, and failure of coping strategies.

\section{Endocrine System}

\section{Polycystic Ovary Syndrome}

Polycystic ovary syndrome (PCOS) constitutes one of the most common endocrine disorders in young women of reproductive age [68] and is closely related to MeS. The prevalence of visceral obesity in women with PCOS varies between 61 and 76\% [69]. As in $\mathrm{MeS}$, visceral obesity in PCOS is associated with elevated levels of LDL, triglycerides, and cholesterol as well as decreased levels of HDL and results in an increased risk of arteriosclerosis [70]. Clearly, PCOS is related to an impaired metabolic homeostasis and thus with an elevated cardiovascular risk [71].

\section{Subclinical Hypercortisolism}

The link between hypercortisolism and MeS was recognized based on similar clinical manifestations. In particular, subclinical hypercortisolism, which is defined as disturbed hypothalamus-pituitary-adrenal (HPA) axis activity without symptoms of an overt Cushing's syndrome or presence of an adrenal incidentaloma, has been linked to MeS [72]. In contrast, it has also been postulated that $\mathrm{MeS}$ is associated with a hyperactivity of the HPA axis [73, 74]. The prevalence of subclinical hypercortisolism has been estimated to be $0.2-2.0 \%$ in the adult population and thereby represents a key suspect for developing MeS [75]. Still, and despite the correlation of subclinical hypercortisolism with visceral obesity [76], hypertension [77], IR [78], and increased cardiovascular risk [79], the clinical significance in MeS still remains unclear.

\section{Disclosure Statement}

The authors disclose any sponsorship or funding arrangements as well as any possible conflicts of interest.

\section{References}

1 Kesse-Guyot E, Julia C, Andreeva V, Fezeu L, Hercberg S, Galan P: Evidence of a cumulative effect of cardiometabolic disorders at midlife and subsequent cognitive function. Age Ageing 2015;44:648-654.

2 Sims EA: Are there persons who are obese, but metabolically healthy? Metabolism 2001;50:1499-1504.

3 Despres JP: Is visceral obesity the cause of the metabolic syndrome? Ann Med 2006;38:52-63.

4 Seidell JC, Han TS, Feskens EJ, Lean ME: Narrow hips and broad waist circumferences independently contribute to increased risk of non-insulin-dependent diabetes mellitus. J Intern Med 1997;242:401-406.

5 Yusuf S, Hawken S, Ounpuu S, Bautista L, Franzosi MG, Commerford P, Lang CC, Rumboldt Z, Onen CL, Lisheng L, Tanomsup S, Wangai P Jr, Razak F, Sharma AM, Anand SS; Interheart Study Investigators: Obesity and the risk of myocardial infarction in 27,000 participants from 52 countries: a case-control study. Lancet 2005;366:1640-1649.

6 Tchernof A, Despres JP: Pathophysiology of human visceral obesity: an update. Physiol Rev 2013;93:359404.
7 Arsenault BJ, Lemieux I, Despres JP, Wareham NJ, Kastelein JJ, Khaw KT, Boekholdt SM: The hypertriglyceridemic-waist phenotype and the risk of coronary artery disease: results from the EPIC-Norfolk prospective population study. CMAJ 2010;182:1427-1432.

8 Hayashi T, Boyko EJ, Leonetti DL, McNeely MJ, Newell-Morris L, Kahn SE, Fujimoto WY: Visceral adiposity and the prevalence of hypertension in Japanese Americans. Circulation 2003;108:1718-1723.

9 Poirier P, Lemieux I, Mauriege P, Dewailly E, Blanchet C, Bergeron J, Despres JP: Impact of waist circumference on the relationship between blood pressure and insulin: the Quebec Health Survey. Hypertension 2005; 45:363-367.

10 Graner M, Siren R, Nyman K, Lundbom J, Hakkarainen A, Pentikainen MO, Lauerma K, Lundbom N, Adiels M, Nieminen MS, Taskinen MR: Cardiac steatosis associates with visceral obesity in nondiabetic obese men. J Clin Endocrinol Metab 2013;98: 1189-1197.

11 Iacobellis G, Singh N, Wharton S, Sharma AM: Substantial changes in epicardial fat thickness after weight loss in severely obese subjects. Obesity (Silver Spring) 2008;16:1693-1697.
Rosito GA, Massaro JM, Hoffmann U, Ruberg FL, Mahabadi AA, Vasan RS, O’Donnell CJ, Fox CS: Pericardial fat, visceral abdominal fat, cardiovascular disease risk factors, and vascular calcification in a communitybased sample: the Framingham Heart Study. Circulation 2008;117:605-613.

13 Wong CX, Ganesan AN, Selvanayagam JB: Epicardial fat and atrial fibrillation: current evidence, potential mechanisms, clinical implications, and future directions. Eur Heart J 2016;DOI: 10.1093/eurheartj/ehw045.

14 Ferrante AW Jr: Obesity-induced inflammation: a metabolic dialogue in the language of inflammation. J Intern Med 2007;262:408-414.

15 van Wijk DF, Boekholdt SM, Arsenault BJ, AhmadiAbhari S, Wareham NJ, Stroes ES, Khaw KT: C-reactive protein identifies low-risk metabolically healthy obese persons: the European Prospective Investigation of Cancer-Norfolk Prospective Population study. J Am Heart Assoc 2016;5:DOI: 10.1161/JAHA.115.002823.

16 Furukawa S, Fujita T, Shimabukuro M, Iwaki M, Yamada Y, Nakajima Y, Nakayama O, Makishima M, Matsuda M, Shimomura I: Increased oxidative stress in obesity and its impact on metabolic syndrome. J Clin Invest 2004;114:1752-1761. 
17 Weisberg SP, McCann D, Desai M, Rosenbaum M, Leibel RL, Ferrante AW Jr: Obesity is associated with macrophage accumulation in adipose tissue. J Clin Invest 2003;112:1796-1808.

18 Dong M, Ren J: What fans the fire: insights into mechanisms of leptin in metabolic syndrome-associated heart diseases. Curr Pharm Des 2014;20:652-658.

19 Lee SW, Jo HH, Kim MR, You YO, Kim JH: Association between metabolic syndrome and serum leptin levels in postmenopausal women. J Obstet Gynaecol 2012;32:73-77.

20 Wannamethee SG, Tchernova J, Whincup P, Lowe GD, Rumley A, Brown K, Cherry L, Sattar N: Associations of adiponectin with metabolic and vascular risk parameters in the British Regional Heart Study reveal stronger links to insulin resistance-related than to coronory heart disease risk-related parameters. Int J Obes (Lond) 2007;31:1089-1098.

21 El-Haschimi K, Lehnert H: Leptin resistance - or why leptin fails to work in obesity. Exp Clin Endocrinol Diabetes 2003;111:2-7.

22 Schulz C, Paulus K, Johren O, Lehnert H: Intranasal leptin reduces appetite and induces weight loss in rats with diet-induced obesity (DIO). Endocrinology 2012; 153:143-153.

23 Srikanthan K, Feyh A, Visweshwar H, Shapiro JI, Sodhi K: Systematic review of metabolic syndrome biomarkers: a panel for early detection, management, and risk stratification in the West Virginian population. Int J Med Sci 2016;13:25-38.

24 Matsuzawa Y, Funahashi T, Kihara S, Shimomura I: Adiponectin and metabolic syndrome. Arterioscler Thromb Vasc Biol 2004;24:29-33.

25 Wang ZV, Scherer PE: Adiponectin, the past two decades. J Mol Cell Biol 2016;8:93-100.

26 Yuan G, Qian W, Pan R, Jia J, Jiang D, Yang Q, Wang S, Liu Y, Yu S, Hu H, Sun W, Ye J, Mao C, Zhuang R, Zhou L: Reduced circulating oxytocin and high-molecular-weight adiponectin are risk factors for metabolic syndrome. Endocr J 2016;63:655-662.

27 Matsushita K, Tamakoshi K, Yatsuya H, Wada K, Otsuka R, Takefuji S, Hotta Y, Kondo T, Murohara T, Toyoshima H: Further inflammatory information on metabolic syndrome by adiponectin evaluation. Int J Cardiol 2008;124:339-344.

28 Kusminski CM, McTernan PG, Schraw T, Kos K, O'Hare JP, Ahima R, Kumar S, Scherer PE: Adiponectin complexes in human cerebrospinal fluid: distinct complex distribution from serum. Diabetologia 2007; 50:634-642.

-29 Qi Y, Takahashi N, Hileman SM, Patel HR, Berg AH, Pajvani UB, Scherer PE, Ahima RS: Adiponectin acts in the brain to decrease body weight. Nat Med 2004;10: 524-529.

30 Hayden MR, Tyagi SC: Homocysteine and reactive oxygen species in metabolic syndrome, type 2 diabetes mellitus, and atheroscleropathy: the pleiotropic effects of folate supplementation. Nutr J 2004;3:4.

31 Catena C, Colussi G, Nait F, Capobianco F, Sechi LA: Elevated homocysteine levels are associated with the metabolic syndrome and cardiovascular events in hypertensive patients. Am J Hypertens 2015;28:943-950

-32 Narin F, Atabek ME, Karakukcu M, Narin N, Kurtoglu S, Gumus H, Coksevim B, Erez R: The association of plasma homocysteine levels with serum leptin and apolipoprotein B levels in childhood obesity. Ann Saudi Med 2005;25:209-214.

33 Howard G, O'Leary DH, Zaccaro D, Haffner S, Rewers M, Hamman R, Selby JV, Saad MF, Savage P, Bergman $\mathrm{R}$ : Insulin sensitivity and atherosclerosis. The Insulin Resistance Atherosclerosis Study (IRAS) Investigators. Circulation 1996;93:1809-1817.
34 Fontes-Carvalho R, Ladeiras-Lopes R, Bettencourt P, Leite-Moreira A, Azevedo A: Diastolic dysfunction in the diabetic continuum: association with insulin resistance, metabolic syndrome and type 2 diabetes. Cardiovasc Diabetol 2015;14:4.

35 Despres JP: Abdominal obesity as important component of insulin-resistance syndrome. Nutrition 1993;9: 452-459.

36 Yue JT, Lam TK: Lipid sensing and insulin resistance in the brain. Cell Metab 2012;15:646-655

37 Mulhall BP, Ong JP, Younossi ZM: Non-alcoholic fatty liver disease: an overview. J Gastroenterol Hepatol 2002;17:1136-1143.

38 Marchesini G, Brizi M, Bianchi G, Tomassetti S, Bugianesi E, Lenzi M, McCullough AJ, Natale S, Forlani G, Melchionda N: Nonalcoholic fatty liver disease: a feature of the metabolic syndrome. Diabetes 2001;50: 1844-1850.

39 Hanley AJ, Williams K, Festa A, Wagenknecht LE, D’Agostino RB Jr, Kempf J, Zinman B, Haffner SM; Insulin Resistance Atherosclerosis Study: Elevations in markers of liver injury and risk of type 2 diabetes: the insulin resistance atherosclerosis study. Diabetes 2004; 53:2623-2632.

40 Angulo P, Lindor KD: Non-alcoholic fatty liver disease. J Gastroenterol Hepatol 2002;17(suppl):S186190.

41 Sears B, Perry M: The role of fatty acids in insulin resistance. Lipids Health Dis 2015;14:121.

42 Tushuizen ME, Bunck MC, Pouwels PJ, Bontemps S, van Waesberghe JH, Schindhelm RK, Mari A, Heine RJ, Diamant M: Pancreatic fat content and beta-cell function in men with and without type 2 diabetes. Diabetes Care 2007;30:2916-2921.

43 Lee Y, Hirose H, Ohneda M, Johnson JH, McGarry JD, Unger RH: Beta-cell lipotoxicity in the pathogenesis of non-insulin-dependent diabetes mellitus of obese rats: impairment in adipocyte-beta-cell relationships. Proc Natl Acad Sci U S A 1994;91:10878-10882.

44 Grundy SM, Cleeman JI, Daniels SR, Donato KA, Eckel RH, Franklin BA, Gordon DJ, Krauss RM, Savage PJ, Smith SC Jr, Spertus JA, Costa F; American Heart Association; National Heart, Lung and Blood Institute: Diagnosis and management of the metabolic syndrome: an American Heart Association/National Heart, Lung, and Blood Institute Scientific Statement. Circulation 2005;112:2735-2752.

45 Tchernof A, Lamarche B, Prud'Homme D, Nadeau A, Moorjani S, Labrie F, Lupien PJ, Despres JP: The dense LDL phenotype. Association with plasma lipoprotein levels, visceral obesity, and hyperinsulinemia in men. Diabetes Care 1996;19:629-637.

46 Lamarche B, Uffelman KD, Carpentier A, Cohn JS, Steiner G, Barrett PH, Lewis GF: Triglyceride enrichment of HDL enhances in vivo metabolic clearance of HDL apo A-I in healthy men. J Clin Invest 1999;103: 1191-1199.

47 Grundy SM: Hypertriglyceridemia, atherogenic dyslipidemia, and the metabolic syndrome. Am J Cardiol 1998;81:18B-25B.

48 Yuan G, Al-Shali KZ, Hegele RA: Hypertriglyceridemia: its etiology, effects and treatment. CMAJ 2007; 176:1113-1120.

49 Verges B: Abnormal hepatic apolipoprotein B metabolism in type 2 diabetes. Atherosclerosis 2010;211:353360.

50 Rizzo M, Berneis K: Small, dense low-density-lipoproteins and the metabolic syndrome. Diabetes Metab Res Rev 2007;23:14-20.

51 Barter PJ, Nicholls S, Rye KA, Anantharamaiah GM, Navab M, Fogelman AM: Antiinflammatory properties of HDL. Circ Res 2004;95:764-772.

52 Ungefroren H, Gieseler F, Fliedner S, Lehnert H: Obesity and cancer. Horm Mol Biol Clin Investig 2015;21: 5-15.
3 Tsugane S, Inoue M: Insulin resistance and cancer epidemiological evidence. Cancer Sci 2010;101:10731079

54 Strong AL, Strong TA, Rhodes LV, Semon JA, Zhang X, Shi Z, Zhang S, Gimble JM, Burow ME, Bunnell BA: Obesity associated alterations in the biology of adipose stem cells mediate enhanced tumorigenesis by estrogen dependent pathways. Breast Cancer Res 2013; 15:R102.

55 Ford ES, Li C, Cook S, Choi HK: Serum concentrations of uric acid and the metabolic syndrome among US children and adolescents. Circulation 2007;115:25262532

56 Bhole V, Choi JW, Kim SW, de Vera M, Choi H: Serum uric acid levels and the risk of type 2 diabetes: a prospective study. Am J Med 2010;123:957-961.

57 Yoo TW, Sung KC, Shin HS, Kim BJ, Kim BS, Kang JH, Lee MH, Park JR, Kim H, Rhee EJ, Lee WY, Kim SW, Ryu SH, Keum DG: Relationship between serum uric acid concentration and insulin resistance and metabolic syndrome. Circ J 2005;69:928-933.

58 Krishnan E, Kwoh CK, Schumacher HR, Kuller L: Hyperuricemia and incidence of hypertension among men without metabolic syndrome. Hypertension 2007; 49:298-303.

59 Pacifico L, Cantisani V, Anania C, Bonaiuto E, Martino F, Pascone R, Chiesa C: Serum uric acid and its association with metabolic syndrome and carotid atherosclerosis in obese children. Eur J Endocrinol 2009; 160:45-52.

60 Kang DH, Park SK, Lee IK, Johnson RJ: Uric acid-induced C-reactive protein expression: implication on cell proliferation and nitric oxide production of human vascular cells. J Am Soc Nephrol 2005;16:3553-3562.

61 Billiet L, Doaty S, Katz JD, Velasquez MT: Review of hyperuricemia as new marker for metabolic syndrome. ISRN Rheumatol 2014;2014:852954.

62 Anand SS, Yi Q, Gerstein H, Lonn E, Jacobs R, Vuksan V, Teo K, Davis B, Montague P, Yusuf S; Study of Health Assessment and Risk in Ethnic Groups; Study of Health Assessment and Risk Evaluation in Aboriginal Peoples Investigators: Relationship of metabolic syndrome and fibrinolytic dysfunction to cardiovascular disease. Circulation 2003; 108:420-425.

63 Kostapanos MS, Florentin M, Elisaf MS, Mikhailidis DP: Hemostatic factors and the metabolic syndrome. Curr Vasc Pharmacol 2013;11:880-905.

64 Faber DR, de Groot PG, Visseren FL: Role of adipose tissue in haemostasis, coagulation and fibrinolysis. Obes Rev 2009; 10:554-563.

65 Elbatarny HS, Netherton SJ, Ovens JD, Ferguson AV, Maurice DH: Adiponectin, ghrelin, and leptin differentially influence human platelet and human vascular endothelial cell functions: implication in obesity-associated cardiovascular diseases. Eur J Pharmacol 2007; 558:7-13

66 Martinac M, Pehar D, Karlovic D, Babic D, Marcinko D, Jakovljevic M: Metabolic syndrome, activity of the hypothalamic-pituitary-adrenal axis and inflammatory mediators in depressive disorder. Acta Clin Croat 2014;53:55-71.

67 Ohaeri JU, Akanji AO: Metabolic syndrome in severe mental disorders. Metab Syndr Relat Disord 2011;9: 91-98.

-68 Azziz R, Woods KS, Reyna R, Key TJ, Knochenhauer ES, Yildiz BO: The prevalence and features of the polycystic ovary syndrome in an unselected population. J Clin Endocrinol Metab 2004;89:2745-2749.

69 Glueck CJ, Dharashivkar S, Wang P, Zhu B, Gartside PS, Tracy T, Sieve L: Obesity and extreme obesity, manifest by ages $20-24$ years, continuing through 32-41 years in women, should alert physicians to the diagnostic likelihood of polycystic ovary syndrome as a reversible underlying endocrinopathy. Eur J Obstet Gynecol Reprod Biol 2005;122:206-212. 
70 Hart R, Norman R: Polycystic ovarian syndrome prognosis and outcomes. Best Pract Res Clin Obstet Gynaecol 2006;20:751-778.

71 Randeva HS, Tan BK, Weickert MO, Lois K, Nestler JE, Sattar N, Lehnert H: Cardiometabolic aspects of the polycystic ovary syndrome. Endocr Rev 2012;33:812841.

72 Mansmann G, Lau J, Balk E, Rothberg M, Miyachi Y, Bornstein SR: The clinically inapparent adrenal mass: update in diagnosis and management. Endocr Rev 2004;25:309-340.

73 Pasquali R, Vicennati V, Cacciari M, Pagotto U: The hypothalamic-pituitary-adrenal axis activity in obesity and the metabolic syndrome. Ann N Y Acad Sci 2006; 1083:111-128.
74 Duclos M, Marquez Pereira P, Barat P, Gatta B, Roger P: Increased cortisol bioavailability, abdominal obesity, and the metabolic syndrome in obese women. Obes Res 2005;13:1157-1166.

75 Chiodini I: Clinical review: Diagnosis and treatment of subclinical hypercortisolism. J Clin Endocrinol Metab 2011;96:1223-1236.

76 Debono M, Prema A, Hughes TJ, Bull M, Ross RJ, Newell-Price J: Visceral fat accumulation and postdexamethasone serum cortisol levels in patients with adrenal incidentaloma. J Clin Endocrinol Metab 2013;98: 2383-2391.

77 Mitchell BM, Webb RC: Impaired vasodilation and nitric oxide synthase activity in glucocorticoid-induced hypertension. Biol Res Nurs 2002;4:16-21.
78 Ivovic M, Marina LV, Vujovic S, Tancic-Gajic M, Stojanovic M, Radonjic NV, Gajic M, Soldatovic I, Micic D: Nondiabetic patients with either subclinical Cushing's or nonfunctional adrenal incidentalomas have lower insulin sensitivity than healthy controls: clinical implications. Metabolism 2013;62:786-792.

79 Di Dalmazi G, Vicennati V, Rinaldi E, Morselli-Labate AM, Giampalma E, Mosconi C, Pagotto U, Pasquali R: Progressively increased patterns of subclinical cortisol hypersecretion in adrenal incidentalomas differently predict major metabolic and cardiovascular outcomes: a large cross-sectional study. Eur J Endocrinol 2012; 166:669-677.

80 Dobbins M, Decorby K, Choi BC: The association between obesity and cancer risk: a meta-analysis of observational studies from 1985 to 2011. ISRN Prev Med 2013;2013:680536. 